\title{
Synthesis of structured triacylglycerols containing medium-chain and long-chain fatty acids by interesterification with a stereoespecific lipase from Mucor miehei.
}

\author{
By Susana Nieto, Julio Sanhueza and Alfonso Valenzuela* \\ * Laboratorio de Lípidos y Antioxidantes, INTA, Universidad de Chile. Casilla 138-11, Santiago, Chile.
}

\section{RESUMEN}

Síntesis de triacilgliceroles estructurados que contienen ácidos grasos de cadena media y larga por interesterificación con una lipasa estereoespecífica de Mucor miehei.

Se describe la preparación de triacilgliceroles estructurados sn-1, sn-3 dilauril, sn-2 ecosapentaenoil glicerol y sn-1, sn-3 dilauril, sn-2 docosahexaenoil glicerol por interesterificación enzimática bajo disponibilidad de agua reducida. Acido laurico, uno de los sustratos para la interesterificación, se obtuvo mediante hidrólisis controlada del aceite de coco por una lipasa no-específica obtenida de Candida cylindracea. Los ácidos grasos se separaron de los productos de hidrólisis mediante cromatografía en columna de resina de plata y convertidos en sus ésteres metílicos. sn-2 Eicosapentaenoil glicerol y sn-2 docosahexaenoil glicerol se prepararon mediante hidrólisis de aceite de pescado por la sn-1, sn-3 lipasa inmovilizada estereoespecifica Lipozyme IM-20 obtenida a partir de Mucor miehe como es descrito en un trabajo anterior. La interesterificación se llevó a cabo en un reactor de vidrio con camisa de agua y los triacilgliceroles se separaron y recuperaron a través de cromatografía en columna de óxido de aluminio. El procedimiento de interesterificación descrito permite obtener a escala de laboratorio triacilgliceroles estructurados que contienen ácidos grasos de cadena media en las posiciones sn-1 y sn-3 y ácidos grasos poliinsaturados de cadena larga de origen marino en la posición sn-2 glicerol.

PALABRAS-CLAVE: Interesterificación - Lipasa (Mucor miehei) Triacilglicerol.

\section{SUMMARY}

Synthesis of structured triacylglycerols containing medium-chain and long-chain fatty acids by interesterification with a stereoespecific lipase from Mucor miehei.

The preparation of structured triacylglycerols sn-1, sn-3 dilauryl, sn-2 eicosapentaenoyl glycerol and sn-1, sn-3 dilauryl, sn-2 docosahexaenoyl glycerol by enzymatic interesterification under restricted water availability is described. Lauric acid, one of the substrates for interesterification, was obtained by the controlled hydrolysis of coconut oil by a non-specific lipase obtained from Candida cylindracea. The fatty acid was separated from the hydrolysis products by silverresin column chromatography and converted to methyl ester. sn-2 Eicosapentaenoyl glycerol and sn-2 docosahexaenoyl glycerol were prepared by the hydrolysis of fish oil by the sn-1, sn-3 stereospecific immobilized lipase Lipozyme IM-20 obtained from Mucor miehei as described in the accompanying paper. The interesterification was carried out in a water jacketed glass reactor and the triacylglycerol products were separated and recovered through aluminum oxide column chromatography. The interesterification procedure described allows to obtain in laboratory scale structured triacylglycerols containing medium-chain fatty acids at the sn-1 and sn-3 positions and long-chain polyunsaturated fatty acid from marine origin at the sn-2 glycerol position.

KEY-WORDS: Interesterification - Lipase (Mucor miehel) Triacylglycerol.

\section{INTRODUCTION}

Physical properties as well as nutritional value of triacylglycerols (TGs) are based not only on the fatty acid composition but also on the positional distribution of the fatty acids bound to glycerol (Heird et al., 1986). The structure of TGs affects absorbability and have different nutritional consequences depending on the type and position of the fatty acids in the glycerol moiety (Bracco, 1994). Therefore the synthesis of TGs containing fatty acids at specific positions and of determined chain length (structured TGs) is of nutritional and industrial importance (Kennedy, 1991). Currently, structured TGs having their sn-2 acyl group substituted with a long-chain fatty acid are noted for their unique nutritional and physiological activity (Ulrich et al., 1996). For example, long-chain polyunsaturated fatty acids contained at the sn-2 position of a TG with medium-chain fatty acids at the sn-1 and sn-3 positions are specifically easily absorbed (Kubow, 1996).

Structured TGs can be obtained by chemically catalyzed interesterification (Marangoni \& Rousseau, 1995). However, it is usually difficult to introduce the desired acyl groups onto the specific positions of glycerol because the reaction occurs randomly with respect to position. In recent years, the use of lipases (triacylglycerol acylhydrolases, EC 3.1.1.3) as biocatalysts for interesterification reactions has become of great potential industrial interest for the production of useful triacylglycerol mixtures and especially for obtaining structured TGs (Valenzuela \& Nieto, 1994). Lipases are esterases that catalyze 
hydrolysis and synthesis of glycerol esters. In transesterification, the acyl moiety is exchanged either between an ester and an acid (acidolysis), ester and alcohol (alcoholysis) or two esters (acyl exchange) (Basheer et al., 1995). Ester hydrolysis is favored under high water availability, but ester synthesis may be conducted under restricted water availability where a minimum quantity of water is necessary for enzyme catalysis to take place (Lindfield et al., 1984). High water concentration in the reaction system shifts the chemical equilibrium toward hydrolysis, and reduced water concentration shifts the equilibrium toward interesterification (Zaks \& Klivanov, 1985).

In this paper we describe the lipase-catalyzed interesterification of two long-chain polyunsaturated acylglycerols, sn-2 eicosapentaenoyl glycerol and sn-2 docosahexaenoyl glycerol, with lauric acid, a saturated medium-chain fatty acid, to obtain two types of structured TGs of potential useful nutritional and/or pharmacological application.

\section{MATERIALS AND METHODS}

Materials. Lipozyme IM-20 (activity 10,000 LU/g, water $7.2 \% \mathrm{w} / \mathrm{w} \%$ ) a microbial lipase obtained from Mucor miehei and immobilized in a macroporous anion exchange resin, was kindly provided by Novo Nordisk A/S (Bagsveard, Denmark). Kieselgel 60 F254 plates, aluminum oxide 90 (Cat. 1076), and silicic acid (A grade) were obtained from E. Merck (Darmstadt, Germany). 2', 7' dichlorofluorescein was purchased from Aldrich (Milwaukee, WI, USA). Coconut oil (95\%, food grade) was locally purchased. Amberlite IR $118 \mathrm{H}$ was purchased from Rohm \& Haas, USA. Hexane, acetone, ethanol, methanol, diethyl ether, acetic acid, and solid reagents were purchased from J. T Baker, USA. Candida cylindracea $(60,000 \mathrm{LU} / \mathrm{g})$, standards of fatty acids, monoacylglycerols and diacylglycerols for thin-layer chromatography and fatty acids standards for gas-chromatography were purchased from Sigma Chemical Company (St. Louis, MO, USA).

Preparation of substrates. Free lauric acid was obtained by hydrolysis of coconut oil with Candida cylindracea as previously described (Nieto et al., 1997). The reaction mixture was washed with methanol ( 1 vol. to precipitate the enzyme) and centrifuged at $2500 \times \mathrm{g}$ for $10 \mathrm{~min}$. The supernatant $(20 \mathrm{~mL})$ was applied to a glass column $(30 \mathrm{~cm} \times 2.5$ $\mathrm{cm}$ i.d.) containing silver-coated Amberlite IR $118 \mathrm{H}$ prepared as described in (Nieto et al, 1997a). The elution profile was assessed at $230 \mathrm{~nm}$. After the supernatant products not fixed to the column (corresponding to the Fo fraction) were eluted, the column was washed first with methanol $95 \%$ ( $F 1$ in the elution pattern), and thereafter with methanol: acetone mixture $(5: 3 \mathrm{v} / \mathrm{v})$ to obtain the $\mathbf{F} 2$ elution fraction. Finally, the column was washed with acetone to elute the rest of the hydrolysis products. The column can be washed in a countercurrent manner with methanol an reused several times. Constituent fatty acids in each fraction were identified by gas-chromatography. Under the experimental conditions F2 is constituted almost exclusively of lauric acid (95\%), which after treatment with $\mathrm{NaOH}$ in methanol according to Totani \& Hara (1991) is converted to the methyl ester derivative and extracted from the mixture with hexane. sn-2 Eicosapentaenoyl- (95\%-98\%) and sn-2 docosahexaenoyl glycerol (94\%-96\%) were prepared from freshly obtained refined sardine oil as described by Nieto et al., (1998).

Interesterification reaction. The course of the interesterification reaction was followed by determining the variation of the concentration of substrates and products with time. For a typical interesterification reaction $20 \mathrm{~g}$ (93 mmoles) of lauric acid methyl ester were mixed with $11.8 \mathrm{~g} \mathrm{(30} \mathrm{mmoles)} \mathrm{of} \mathrm{sn-2}$ eicosapentaenoyl glycerol or with $12.6 \mathrm{~g} \mathrm{(30}$ mmoles) of docosahexaenoyl glycerol in a $150 \mathrm{~mL}$ water-jacketed $\left(40{ }^{\circ} \mathrm{C}\right)$ glass reactor. The substrates were previously mixed with anhydrous sodium sulfate to eliminate residual water. The mixture was dissolved in $50 \mathrm{~mL}$ of hexane previously saturated with $0.2 \%$ of water (Goh et al., 1993). $4 \mathrm{~g}$ of Lipozyme IM-20 (previously treated with anhydrous sodium sulfate) were added to each reaction batch and the interesterification was carried out under magnetic stirring at $200 \mathrm{rpm}$ for different times until a maximum of 20 hours. At various times during incubation, $5 \mathrm{~mL}$ of the reaction mixture were withdrawn, centrifuged at $2000 \times \mathrm{g}$ to recover the enzyme (which can be reused several times) and the remaining fatty acid (lauric acid) methyl ester and the TGs formed were identified by TLC. The fatty acid composition of the TGs was assessed by gas-chromatography as described in this section.

Purification of the reaction products. The reaction products $(10-12 \mathrm{~g})$ were passed through aluminum oxide 90 in a glass column $(15 \mathrm{~cm} \times 2.5$ $\mathrm{cm}$, i.d) (Kosugi \& Azuma, 1994). The eluent was diethyl ether. Polar impurities, composed of residual lauric acid methyl ester, the sn-2 monoacylglycerols and some diacylglycerols, were adsorbed on the basic aluminum oxide column and the nonpolar structured TGs were eluted with the diethyl ether. The elution profile was assessed spectrophotometrically at $360 \mathrm{~nm}$. The solvent was evaporated by bubbling dry N2 and pure structured TGs were stored in sealed flasks under $\mathrm{N} 2$ at $-20^{\circ} \mathrm{C}$ until use.

Analytical methods. Water contents in the reaction system were measured with a Karl Fisher Titrator 684 KF (Metrohm, Herisau, Switzerland). 
Qualitative analyses of sn-2 eicosapentaenoyl glycerol, sn-2 docosahexaenoyl glycerol, and of the interesterification products (sn-1, sn-3 dilauryl, sn-2 eicosapentaenoyl or docosahexaenoyl glycerol) were carried out by TLC. Samples were diluted 1:10 $(\mathrm{v} / \mathrm{v})$ with ethanol, and $0.01 \mathrm{~mL}$ of the diluted samples were used for TLC analysis. Hexane/diethyl ether/acetic acid (80:20:1) was used as solvent on Kieselguhr 60 F254 plates with one hour running time. Slightly dried plates were sprayed with $0.1 \% 2$, 7'- dichlorofluorescein in $99.5 \%$ ethanol for detecting the spots at $254 \mathrm{~nm}$ (for monoacylglycerols) and 360 $\mathrm{nm}$ (for triacylglycerols) (Linko et al., 1994). Fatty acid methyl esters were prepared by interesterification with a boron trifluoride-methanol mixture (Morrison \& Smith, 1984). Gas-chromatography was carried out in a Hewlett Packard 5890 series II chromatograph equipped with split injector and a flame ionization detector, and using a SP-2560 (Supelco, Inc, Bellefonte, PA, USA) capillary column (100 $\mathrm{m} \times 0.25$ $\mathrm{mm}$ i.d.). The column temperature was raised from $150{ }^{\circ} \mathrm{C}$ to $210{ }^{\circ} \mathrm{C}$ at $5{ }^{\circ} \mathrm{C} / \mathrm{min}$. The injector and detector temperatures were both $250^{\circ} \mathrm{C}$. Hydrogen was used as carrier gas (Tamaka et al., 1994).

\section{RESULTS AND DISCUSSION}

Figure 1 shows the elution profile of the Fo, F1 and $\mathbf{F} 2$ fractions after the separation of the products of the enzymatic hydrolysis of coconut oil through silver-coated Amberlite IR $118 \mathrm{H}$ column chromatography. Gas-chromatograph analysis of the F2 fraction confirms that it is mainly composed (95\%-98\%) by lauric acid (data not shown). Lauric acid was converted to the methyl ester derivative which was used as substrate for the interesterification reaction. Figure 2-A shows the kinetic of the enzymatic interesterification reaction between methyl laureate and sn-2 eicosapentaenoyl glycerol to form the expected product sn-1, sn-3 dilauryl, sn-2 eicosapentaenoyl glycerol, and Figure 2-B shows the reaction of the same medium-chain fatty acid methyl ester with sn-2 docosahexaenoyl glycerol to form the expected sn-1, sn-3 dilauryl, sn-2 docosahexaenoyl glycerol. The kinetic of both reactions shows similar yields for the formation of TGs, but the synthesis of the eicosapentaenoyl-derivative occurs faster than the synthesis of the docosahexaenoyl-derivative. The different reaction speed may be probably due to the more complex spatial configuration of the sn-2 docosahexaenoyl glycerol compared to the sn-2 eicosapentaenoyl glycerol. The fomer compound is two carbon longer and has one more double bond than the sn-2 eicosapentaenoyl-derivative. Although no positional analysis of the triacylglycerols was carried out, the presence of only one spot corresponding to TGs in the TLC assay carried out at the end of each interesterification reaction suggest that the synthesis of the desired product occurred. The preparation of several grams of each structured TG can be achieved by increasing the concentration of both substrates in the interesterification reaction followed by the separation of the respective TGs through aluminum oxide column-chromatography. The laboratory-scale preparation of these products allows the assay of their incorporation to more complex mixtures, providing the TGs are properly stabilized to oxidation by antioxidants.

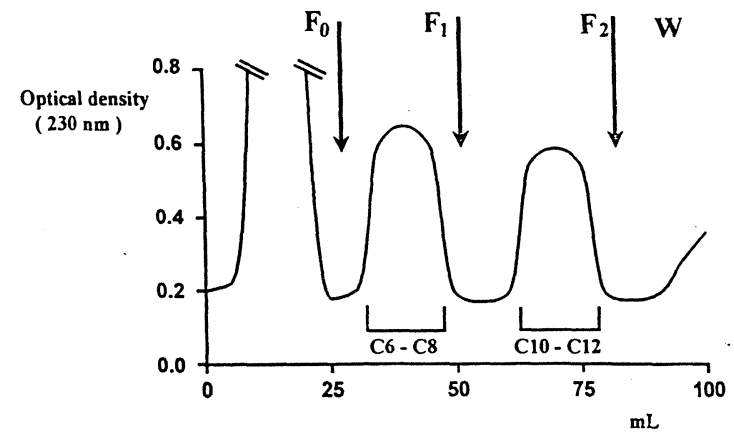

Figure 1

Separation of lauric acid by silver-coated Amberlite IR $118 \mathrm{H}$ column chromatography from the products of the enzymatic hydrolysis of coconut oil. Fo: hydrolysis products non-adsorbed the column. F1: fraction eluted by methanol

95\%. F2: fraction eluted by methanol:acetone $(5: 3 \mathrm{v} / \mathrm{v})$. W: washing with acetone. The elution profile represents a typical separation procedure.

A

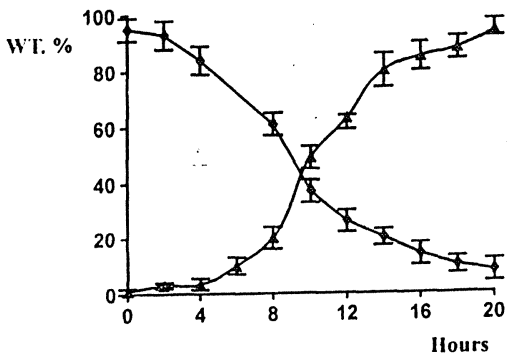

B

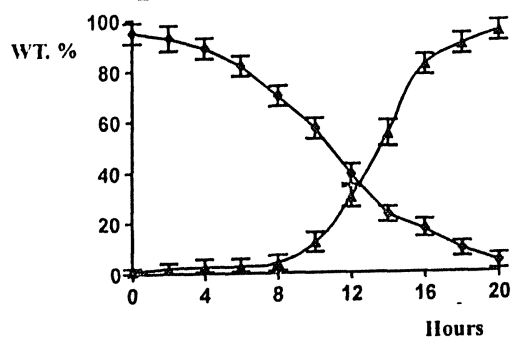

$\star$ Trlacylglycerol

- Lauric Acld

Figure 2

Kinetics of the interesterification reaction between methyl laureate and sn-2 eicosapentaenoyl glycerol (A) or sn-2 docosahexaenoyl glycerol (B), catalyzed by the immobilized lipase Lipozyme IM-20. Each point represents the mean of 4 assays \pm S.D. Other experimental conditions are in the text. 
The results reported in the present investigation demonstrate the potentials of lipase-catalyzed interesterification of medium-chain fatty acid methyl esters and sn-2 long-chain polyunsaturated monoacylglycerols to obtain structured TGs (Huang \& Akoh, 1996). Structured TGs containing medium-chain fatty acids at the sn-1, sn-3 positions and long-chain polyunsaturated fatty acid at the sn-2 position, such as eicosapentaenoic acid or docosahexaenoic acid, can provide both essential fatty acid and quick metabolic energy (Kritchevsky, 1995). Such products can be synthesized by means of sn-1, sn-3 specific lipases, but not with chemical catalysts. The use of medium-chain fatty acid methyl ester as acyl donors has some advantages, such a high reaction rate, no inhibition at high substrate molar ratio and high substrate concentration, as opposed to use free acid form (Basheer et al., 1995). Structured TGs obtained by enzymatic interesterification offer considerable commercial potential and may favorably compete with oil seeds containing medium-chain fatty acids that may be produced through genetic engineering and with structured TGs produced via chemical catalysis (Quinlan \& Moore, 1993).

\section{ACKNOWLEDGMENTS}

This research was supported by FONDECYT, project 1940422.

\section{REFERENCES}

Basheer, S., Mogi, K., and Nakajima, M. (1995).«Interesterification kinetics of triglyceride and fatty acids with modified lipases in n-hexane".-J. Am. Oil Chem. Soc. 72, 511-518.

Bracco, U. (1994). - «Effect of triglyceride structure on fat absorption".-Am. J. Clin. Nutr. 60 (suppl), 1002S-1009S.

Dinamarca, E., Garrido, F., and Valenzuela, A (1990). - «Simple high vacuum distillation equipment for deodorizing fish oil for human consumption".Lipids 25, 170-171.

Goh, S. H, Yeong, S. K., and Wang, C. W. (1993)."Transesterification of cocoa butter by fungal lipases: Effect of solvent on 1,3-specificity".-J. Am. Oil Chem. Soc. 70, 567-570.

Heird, W. C., Grundy, S. M., and Van Hubbard, S. (1986)."Structured lipids and their use in clinical nutrition".Am. J. Clin. Nutr. 43, 320-324.

Huang, K., and Akoh, C. (1996)._- «nzymatic synthesis of structured lipids: Transesterification of triolein and caprylic acid ethyl ester".-J. Am. Oil Chem. Soc. 73, 245-250.

Kennedy, J. (1991). - «Structured lipids: fats for the future».Food Technol. 45, 76-83.
Kosugi, Y., and Azuma, N. (1994).— «Synthesis of triacylglycerol from polyunsaturated fatty acid by immobilized lipase».-J. Am. Oil Chem. Soc. 71, 1397-1403.

Kritchevsky, D. (1995)._ «Fatty acids, triglycerides structure, and lipid metabolism".-Nut. Biochem. 6 , 172-178.

Kubow, S. (1996).- «The influence of positional distribution of fatty acids in native, interesterified and structurespecific lipids on lipoprotein metabolism and atherogenesis".-Nut. Biochem. 7, 530-541.

Lindfield, W. M., Barauskas, R. A.., Siviere, L., Serota, S., and Stevenson, R. W. (1984).-—Enzymatic fat hydrolysis and synthesis".- J. Am. Oil Chem. Soc. 61, 191-195.

Linko, Y. Y., Lamsa, M., Huhtala, A., and Linko, P. (1994)._- «ipase-catalyzed transesterification of rapeseed oil and 2-ethyl-1-hexanol».-J. Am. Oil Chem. Soc. 71, 1411-1414.

Marangoni, A., and Rousseau, D. (1995).—-Engineering triacylglycerols: The role of interesterification".Trends Food. Sci. Technol. 6, 329-335.

Morrison, W. R., and Smith, L. M. (1984).- - Preparation of fatty acid-methyl esters and dimethilacetals from lipids with boron fluoride».- J. Lipid Res. 5, 600-608.

Nieto, S., Rodríguez., R., Sanhueza, J., and Valenzuela, A. (1997).- - Hydrolysis of coconut oil (Cocos nucífera L.) by stereo-specific and non stereoespecific enzymes".-Grasas y Aceites 48, 6-10.

Nieto, S., Córdova, A. M., Sanhueza, J., and Valenzuela, A. (1997a).- «Obtention of highly purified fractions of eicosapentaenoic acid and docosahexaenoic acid from sardine oil by silver-resin chromatography: A semi preparative procedure».-Grasas y Aceites 48, 197-199.

Nieto, S., Gutiérrez, J., Sanhueza, J., and Valenzuela, A. (1999). - «Preparation of sn-2 long-chain polyunsaturated monoacylglycerols from fish oil by hydrolysis with a stereoespecific lipase from Mucor miehei».-Grasas y Aceites 50, 111-113.

Quinlan, P., and Moore, S. (1993).- «Modification of triglyceride by lipases: Process technology and its application to the production of nutritionally improved fats".-INFORM 4, 580-585.

Totani, Y., and Hara, D. (1991)._ «Preparation of polyunsaturated phospholipids by lipase-catalyzed transesterification».-J. Am. Oil Chem. Soc. 68, 848-851.

Tanaka, Y., Hirano, J., and Funada, T. (1994)._- «Synthesis of docosahexaenoic acid-rich triglyceride with immobilized Chromobacterium viscosum lipase».-J. Am. Oil Chem Soc. 71, 331-334.

Ulrich, H., McCarthy, S., Katz, D., and Kvetan, V. (1996).«Parenteral use of medium-chain triglycerides: A reappraisal».-J. Nutrition 12, 231-238.

Valenzuela, A., and Nieto, S. (1994)._-Biotechnology of lipids: The use of lipases for the structural modification of fats and oils».-Grasas y Aceites 45, 337-343.

Zaks, A., and Klivanov, A. M. (1985)._- «nzyme-catalyzed process in organic solvents".-Proc. Natl. Acad. Sci. USA. 82, 3192-3199. 